\title{
YERKÖY'DE BİTKİ ADLARINDAN OLUŞAN YER ADLARI
}

\begin{abstract}
Arş. Gör. Ayşegül KUŞDEMİR*
ÖZ: Yer adları, bir milletin yerleşme tarihindeki en önemli canlı belgelerinden biridir. Bir yeri kendisine vatan yapan milletlerin o yere verdiği isim, o milletin izlerini taşır. Kişilerin düşünceleri ve duyguları ile yerleşim yerinin adı arasında sıkı bir bağlantı vardır. Yer adlarını yapı, anlam ve köken bakımından inceleyen bilim koluna "toponimi" denir. Toponimilerde bütün yer adları, köy ve şehir gibi yerleşme yerlerinin adları ve tabiî yer adları dikkate alınır. Toponimler kavram işareti oldukları objenin büyüklüğüne göre makrotoponimler ve mikrotoponimler şeklinde gruplara ayrılır. Mikrotoponimler doğal coğrafi alanda, yalnızca o coğrafyanın sakinleri tarafından kullanılan, 1/100.000 ölçekli haritalarda bile anılmayan ağızdan ağıza, kulaktan kulağa, nesilden nesile aktarılarak günümüze kadar ulaşmış her türlü yer adlarıdır. Mikrotoponimi çalışmaları bir yörenin dil zenginliğinin tespiti için oldukça önemlidir. Türkçede yer adlarını belirleyen faktörlerden biri adlandırılacak yerin bitki örtüsüdür. $\mathrm{Bu}$ makalede Yerköy ilçesine bağlı köylerdeki bitki adlarından kurulmuş yer isimlerine değinilecektir. Yer adlarında, hangi bitkilerin ne yoğunlukta görüldüğü belirlenmiştir. Yer adlandırılmalarında bitkilerin kullanım sıklığı tespit edilerek durumun iklim ve bitki örtüsüyle ilişkisine dikkat çekilecektir. Bu yer adlarının kuruluşunda görev alan ilgi çekici unsurlar da tespit edilmiştir. Bu unsurlar bugün sadece Derleme Sözlüğü’nde yaşamaktadırlar. Bunların tespit edilmesi dil bilimine katkı sağlayacaktır.
\end{abstract}

Anahtar Kelimeler: Ad bilimi, yer adları bilimi, mikrotoponimi, Yerköy, bitki adları.

\section{Place Names Composed of Plant Names in Yerköy}

ABSTRACT: The names of places are one of the most important alive documents in the history of a nation. The name given to a place bears traces of the nations that make the place their homeland. There is a

* Amasya Üni. Fen-Edebiyat Fak. TDE Böl. aysegulkusdemir@hotmail.com 
strong relationship between the thoughts and feelings of people and the name of the places. The field investigating the names of places with respect to meaning, root and structure is called "toponymy". The names of villages, cities and natural whereabouts are all taken into consideration in toponyms. Toponym can be divided into two categories as macrotoponymy and microtonymy according to the size of the object they refer to. Microtoponyms which were transmitted by word of mouth to the next generations and reached to these days, are the names of places that are just used by the residents of that geography in natural settings and not stated even in 1/100.000 scale maps. Microtoponymics is quite important to detect language richness of that region. One of the factors that are used in assigning place names in Turkish is plant cover. In this article, investigating the microtoponyms of villages in Yerköy, place names originated from plant names are dealt with. The intensity of plants used in place names are stated. By determining the intensity of the use of plants in naming places, attention will be drawn to the relationship between climate and vegetation. Interesting factors in assigning place names have also been identified. Today, we can only see these factors in the Compilation Dictionary and identification of them will contribute to linguistics.

Keywords: Onomastics, toponymy, microtoponymy, Yerköy, plant names.

Türk yer adlarının verilişinde bitkilerden yaralanma eğilimi çok eskiden beri mevcuttur. Yörenin bitki örtüsü, faydasına inanılan, gıda hazırlamada kullanılan, kutsal ya da önemli endemik bitkiler yer adı vermede baş temayüllerdendir. Bu konuda çeşitli çalışmalar yapılmış; ancak standart dilde görülen bitki adlarından bahsedilmiş, ağılarda görülen bitki isimlerine fazla yer verilmemiştir. Yapılan çalışmalar makro düzeyindeki yer adlarından elde edildiğinden daha küçük yerleşim birimlerindeki bitki isimleri üzerine gidilmemiştir.

Çalışmamızda bu eksikliği aza da olsa gidermek adına Yozgat ilinin Yerköy ilçesine bağlı yer adlarını incelemiş bulunuyoruz. Yer adlarından kastımız ilçeye bağlı köylerdeki mikrotoponimlerdir. Mikrotoponimler doğal coğrafi alanda, yalnızca o coğrafyanın sakinleri tarafından kullanılan, 1/100.000 ölçekli haritalarda bile anılmayan ağızdan ağıza, kulaktan kulağa, nesilden nesile aktarılarak günümüze kadar ulaşmış her türlü yer adlarıdır. (Şahin 2011: 1808) Bu mikrotoponimlerde geçen standart dile ve yöre ağzına ait bitki isimlerinden oluşmuş yer adları çalışmamızın konusunu oluşturmaktadır. 
TÜBAR XLI / 2017-Bahar / Yerköy'de Bitki Adlarından Oluşan Yer Adları

Yerköy yer adlarında görülen bitki isimlerinin ele alındığı bu çalişma şu esaslar üzerine kurulmuştur:

1. Yer adları tabiri Yozgat'ın Yerköy ilçesine bağlı altmış köyün mikrotoponimilerini içerir.

2. Yer adları sahada yapılan derleme çalışmalarının sonucunda tespit edilmiştir.

3. Çalışmada toplam 146 bitki adından oluşmuş yer isimleri tespit edilmiştir.

4. Bitki adlarından oluşan bu yer isimleri 47 türü içerir. Bu türlerden 11'i ağızlarda, 31'i standart dilde 5'i de hem ağızlarda hem standart dilde yaşamaktadır.

5. Alfabetik olarak sıralayacağımız bu yer isimlerinin bulunduğu yerleşim birimi parantez içinde gösterilecektir.

Alıç (Crataegus sp. L.) : Kışın yapraklarını döken ağaç veya ağaççıklardır. Dalları genellikle dikenli, çiçekleri beyaz veya pembe renkli, meyveleri sarı, kırmızı, koyu kırmızı veya siyah renklidir. (Baytop 2007: 29) Bu bitki ismiyle ilgili tespit ettiğimiz yer adları şunlardır:

Alıçlı (<alıç+lı "Beserek köyünde bir mevki adı")

İhsanınalıç (<İhsan'ın alıç "Küçükçalıklı köyünde bir mevki adı")

Araka (Pisum Sativum L.) Taneleri iri olan, bir çeşit bezelye türü. (Seçmen vd. 1998: 240) Bu bitki ismiyle ilgili bir yer adı tespit edilmiştir:

Araĥhınındeğarmen: (<araka+nın değirmen "Karacaağaç köyünde bir mevki adı")

Ardıç (Juniperus sp. L.) Kışın yapraklarını dökmeyen ağaç veya ağaççıklardır. Bu türlerin meyveleri tedavi alanında kullanılır. Bazı türlerinden katran da elde edilir. (Baytop 2007: 33) Bu bitki ismiyle ilgili iki yer adı tespit edilmiştir:

Ardıçlar: (<ardıç+lar "Çamdibi köyünde bir mevki adı)

Çadırardıçyolu: (<çadır ardıç yolu "Beserek köyünde bir yol adı")

Armut (Pyrus sp. L.) Her iki yarıkürenin 1lıman iklim kuşağ 1 ülkelerinde yetiştirilen armut, dünyanın en önemli meyve ağaçlarından biridir. Armut ağacı tepeye doğru genişleyen ve olgunlaştığında 13 metreye ulaşan boyuyla elma ağacından daha uzun ve daha diktir. (Seçmen vd. 1998: 234) Tespit ettiğimiz yer adları şunlardır:

Ăgarmud (<ak armut "Sedir köyünde bir bahçe adı")

Armudlu (<armut + lu "Hacıuşağı köyünde bir tepe adı")

Armudlu (<armut+lu "Kömüşören köyünde bir mevki adı") 
Armutlu (<armut+lu "Belkavak köyünde bir mevki adı")

Armudludepe (<armut+lu tepe "Beserek köyünde bir tepe adı")

Niyazınarmut (<Niyaz'ın armut "Küçükçalıklı köyünde bir bahçe adı")

Arpa (Hordeum sp. L.) Buğdaygillerden taneleri malt ve yem olarak kullanılan önemli bir tahıl bitkisidir. (Seçmen vd. 1998: 317) Bu bitki adıyla ilgili bir yer adı tespit edilmiştir.

Arpalıh (<arpa+lık "Beserek köyü ile Topaç köyü arasında kalan mevki adi)

Asma (Vitis sp. L.) Karmaş1k yapılı, kahverengi gövdesi olan yarı odunsu bitkilerdir. Parçalı, üzeri tüylerle kaplı yaprakları vardır. Sarı, yeşil, siyah meyveleri vardır. (Vikipedi, https://tr.wikipedia.org/wiki/Asma )Bu bitki adı ile ilgili iki yer adı tespit edilmiştir.

Asmalıh: (<asma+lıh "Karlı köyünde bir mevki adı")

Asmanınbayır: (<asma+nın bayır "Karlı köyünde bir tepe adı")

Ayva (Cydonia oblonga Miller) Dört-beş metre boylanan kahverengi gövdeli meyve ağacıdır. Çiçekleri pembe veya beyazdır. Ülkemizde meyvesi için yetiştirilir. ( Seçmen-vd.1998: 234) Bir yer adında tespit edilmiştir.

Ayvabağları (<ayva bağları "Kördeve köyünde bir bağ adı)

Badem (Amygdalus orientalis Miller): Meyvesi yenebilen küçük bir ağaç türü. Badem de bu ağacın meyvesidir. ( Aksoy-Budak 2004: 116) Badem bitkisi ile ilgili üç yer adı tespit edilmiştir.

Bademgaya (<badem kaya "Kördeve köyünde bir bağ adı")

Bademgayası (<badem kayası "Cakcak köyünde bir bağ adı")

Bademgayadepesi (<badem kaya tepesi "Karaosmanoğlu köyünde bir tepe ad1")

Bırçalık (Scorzonera sp. L.) Çok yıllık, rizomlu, sarı çiçekli ve otsu bir bitkidir. Rizomunun iç kısmı yenir. (Baytop 2007: 47) Bu bitki ismi ile ilgili bir yer adı tespit edilmiştir.

Bırçalıhdepesi (<bırçalık tepesi "Aşağıelmahacılı köyünde bir tepe adı.")

Boruk (Jasminium fruticans L.) Anadolu'da yabani olarak yetişen sarı çiçekli tırmanıcı bir bitki, katırtırnağı. (Baytop 2007: 281) Bu bitki adıyla ilgili dört yer adı tespit edilmiştir.

Boruhlu ( < boruk+lu "Kayadibi köyünde bir mevki adı")

Boruhlu ( < boruk+lu "Kördeve köyünde bir mevki adı")

Poruhlu (<boruk+lu "Büyükçalıklı köyünde bir mevki adı")

Poruhlununpuñar $(<$ boruk+lu+nun pınar "Büyükçalıklı köyünde bir çeşme adı") 
TÜBAR XLI / 2017-Bahar / Yerköy’de Bitki Adlarından Oluşan Yer Adları

Bostan (Citrullus sp. . Schrad. ex Eckl. \& Zeyh.) Sicak ve 1lıman iklimlerde yetişen sulu bir meyve ad1, karpuz. (Seçmen-vd.1998: 211) Bu meyve adı ile ilgili bir yer adı tespit edilmiştir.

Bostanarhacı (<bostan arkacı "Topaç köyünde bir mevki adı")

Cehrilik (Paeonia sp. L.) İlkbaharda açmaya başlayan, yaprakları pembe, Yozgat yöresinin endemik bir bitki türünün adıdır. (Baytop 2007: 38) Aslında bir şakayık türüdür. Bu endemik bitki türü ile ilgili iki yer adı tespit edilmiştir.

Cehillik (<cehrilik "Kahya köyünde bir mevki adı")

Cehilliğindere ( < cehillik+in dere "Kahya köyünde bir derenin adı")

Ceviz (Juglans regia L.) Yirmi beş otuz metre kadar yükselebilen ve k1şın yapraklarını döken bir ağaçtır. Anadolu'da yabani olarak bulunduğu gibi park ve bahçelerde de yetiştirilir. (Baytop 2007: 58) Cevizle ilgili üç yer adı tespit edilmiştir.

Cevizindibi (< ceviz+in dibi "Hacılı köyünde bir çeşme adı")

Cevizlidepesi (<ceviz+li tepesi "Delice köyünde bir tepe adı")

Feriinceviz ( $<$ Ferik+in ceviz "Yakuplu köyünde bir bağ adı")

Çam (Pinus nigra Arn.) :Kara çam. Otuz - kırk metre kadar boylanabilen, yaprakları yedi ile on sekiz santimetre olabilen koyu yeşil ve sert olan çam türüdür. ( Seçmen-vd.1998: 126) Çam ile ilgili üç yer adi tespit edilmiştir.

Çamaandere (<çam+lı alan dere "Topaç köyünde bir dere adı")

Çamcıbağları ( <çam+cı bağları "Karacaahmetli köyünde bir bağ adı")

Çamlıh (<çam+lık "Yukarıeğerci köyünde bir koru adı")

Çavdar (Secale sp. L.) Soğuğa dayanıklı, kumlu ve gevşek toprakları seven bir tahıl bitkisidir ( Seçmen-vd.1998: 317) Bu bitki adı ile ilgili bir yer adı tespit edilmiştir.

Çavdar (<çavdar "Poyraz köyünde bir tarla adı")

Çiğdem (Crocus sp. L.): Ankara çiğdemi. Özellikle Orta Anadolu Bölgesi'nde yetişir. İlkbaharda parlak sarı renkli çiçekler açar.Yumruları ile çiğdem pilavı yapılır. (Baytop 2007: 72) Yozgat'ta da bu bitkinin pilavı yapılır ve şenlikler düzenlenir. Çiğdem ile ilgili yedi yer adi tespit edilmiştir.

Çiğdembayırı (<çiğdem bayırı "Büyükçalıklı köyünde bir tepe adı")

Çiğdemdepe (<çiğdem tepe "Köycü köyünde bir tepe adı")

Çiğdemdepesi (çiğdem tepesi " Orhan köyünde bir tepe adı")

Çiğdemli (çiğdem+li "Poyraz köyünde bir mevki adı")

Çiğdemlik (<çiğdem+lik "Belkavak köyünde bir mevki adı")

Çiğdemlik (<çiğdem+lik "Hatip köyünde bir mevki adı")

Çiğdemlininburun (<çiğdem+li+nin burun "Poyraz köyünde bir tepe adı") 
Çiriş (Eremurus spectabilis Bieb): Yüz - yüz elli santimetre yükseklikte, sarımsı çiçekli ve otsu bir bitkidir. Taze yaprakları sebze olarak kullanılır. Dağ pırasası, yabânî pırasa. (Baytop 2007: 73) Bu bitki ismiyle ilgili bir yer adı tespit edilmiştir.

Çirişlikderesi (<çiriş-+ik deresi "Karacaahmetli köyünde bir dere adı.)

Dut (Morus L.) Meyveleri beyaz, siyah veya siyah morumsudur. (Baytop 2007: 95) İki yer adında tespit edilmiştir.

Dutluh (<dut+luk "Eskiyerköy köyünde bir mevki adı")

Garadutlar (<kara dut+lar "Kördeve köyünde bir mevki adı")

Elma (Malus sylvestris Miller ) Beyaz veya pembe çiçekli, olgun meyveleri yenilebilen ülkemizde geniş kültürü yapılan, yabani olarak da bulunan bir meyve ağacıdır. (Seçmen-vd.1998: 234) Sekiz yer adında tespit edilmiştir.

Elmalağan (<elma+lı alan "Topaç köyüne ait bir koru adı")

Elmalağandepe (<elma +1 alan tepe "Susuz köyünde bir tepe adı")

EImalı (<elma +11 "Kördeve köyüne ait bir

Elmalı (<elma $+l_{1}$ "Sarıyaprak köyüne ait bir

Elmalıbel (<elma- +lı bel "Susuz köyünde bir bağın adı")

Elmalıdepesi (<elma $+l_{1}$ tepesi "Karaosmanoğlu köyünde bir tepe adı")

Elmalık (<elma+lık "Aydıgün köyünde bir tarla adı")

Eskielma (<eski elma "Poyraz köyünde bir bağ adı")

Erik (Prunus sp. Ledeb.) Meyveleri sarı, kırmızı veya mor renklidir. (Baytop 2007: 101) Erikle ilgili iki yer adı tespit edilmiştir.

Erikli (<erik+li "Zencir köyünde bir koru adı")

Erikli (<erik+li seki "Eskiyerköy köyünde bir mevki adı")

Fndık (Corylus avellana L.) Yaban findığı. (Baytop 2007: 107) Sadece bir yer adında tespit edilmiştir. Bu yer adını tespit ettiğimiz köyün rakımı 1300 metreden fazladır. Yüksek dağ yamaçlarında bulunur.

Findıhlı ( $<$ fındık +1 " "Beserek köyünde bir koru adı")

Gelincik (Papaver sp. L.) Tüm Türkiye'de yaygın olan ve genellikle çayırlıklarda, yol kenarlarında vb. yerlerde yetişen, kırmızı çiçekli tek y1llık otsulardır. (Seçmen vd. 1998: 174) Bu bitki ismi ile ilgili bir yer adı tespit edilmiştir.

Gelincikgayası (<gelincik kayası "Çayköy köyünde bir kayalık adı")

Germişek (Viburnum sp. L.) Yaprakları tam, dişli kenarlı, alt yüzü tüylü bir ağaç türü. (Baytop 2007: 119) Ağızlık ve sepet yapımında kullanılır. Bu bitki ismi ile ilgili bir yer adı tespit edilmiştir.

Gerimşeklidere (<germişek+li dere "Beserek köyünde bir derenin adı")

İğde (Elaeagnus angustifolia L.) Yedi metre kadar yükselebilen, dikenli veya dikensiz, sarımsı renkli ve kuvvetli kokulu çiçekli bir ağaç 
veya ağaççıktır. (Baytop 2007: 141) Tespit ettiğimiz iğde isimleri yabani olanlara aittir. İğde ile ilgili on iki yer adı tespit edilmiştir.

Emininiğdeler (<Emin'in iğde+ler "Hacısmanlı köyünde bir koru adı.")

İğdebaşı (<iğde başı "Hacıuşağı köyünde bir tarla adı.")

İğdeli (<iğde+li "Aşağıelmahacılı köyünde bir koru adı.")

İğdeli (<iğde+li "Belkavak köyünde bir mevki adı.")

İğdeli (<iğde+li "Hacıçeşmesi köyünde bir mevki adı.")

İğdeli (<iğde+li "Kördeve köyünde bir mevki ad..")

İğdeli (<iğde+li “Topaç köyünde bir mevki adı.")

İğdelibucah (<iğde+li bucak "Karacaahmetli köyünde bir mevki adı.")

İ̆gdelidere (<iğde+li dere "Kahya köyünde bir dere adı.")

İğdelidere (<iğde+li dere "Topaç köyünde bir dere ad..")

İğdelipuñarı (<iğde+li pınarı "Belkavak köyünde bir pınar adı.")

İğdeliyolu (<iğde+li yolu "Belkavak köyünde bir yol adı.")

Kabak (Cucurbita L.) Kısa gövdeli sürünücü otsulardır. (Seçmenvd.1998: 212) Kabak ile ilgili dört yer adı tespit edilmiştir.

Gabahçıdevrişinbağ (<kabak+çı Derviş’in bağ “Aşağıelmahacılı köyünde bir bağ adı")

Gabahçiçaağ (<kabak çiçeği "Yukarıelmahacılı köyünde bir mevki adı")

Gabahdepesi (<kabak tepesi "Karlı köyünde bir tepe adı")

Gabahyeri (<kabak yeri "Çayköy köyünde bir tarla adı")

Karaçalı (Paliurus sp. Mill.) Karaçalı kışın yaprağını döken, üç metreye kadar boylanabilen, sık dall1, dikenli ve simpodial büyüme yapan, dağınık tepeli bir türdür. Halk arasında Çalıdikeni, Sincandikeni, Karadiken gibi yöresel isimlerle anılmaktadır. Türkiye, Güney Avrupa, Balkanlar ve Kafkaslarda yayılış göstermektedir. (Deligöz vd. 2007: 51-60) Bu bitki adı ile ilgili dört yer adı tespit edilmiştir.

Garaçalı (<karaçalı "Bicikler köyünde bir mevki adı.")

Garaçalı (<karaçalı "Orhan köyünde bir mevki adı.")

Garaçalı (<karaçalı Yukarıeğerci köyünde bir mevki adı.”)

Garaçalı (<karaçalı "Yukarıelmahacılı köyünde bir mevki adı.")

Karamık (Berberis crataegina DC.) İki metre kadar yükselebilen, çok yıllık, çok dikenli, sarı çiçekli ve meyveleri olgunlukta siyah renkte olan bir çalıdır. (Baytop 2007: 157) Karamık bitkisi ile ilgili yörede bir yer adı tespit edilmiştir.

Garamıhlıdere ( $<$ karamık +1 dere "Kahya köyünde bir dere adı.")

Kavak (Populus sp. L.) Kışın yaprağını döken büyük ağaçlardır. (Baytop 2007: 162) Yerköy'de en çok bu ağaç türü ile ilgili yer isimleri tespit edilmiştir. İçinde kavak kelimesi geçen yer adı sayısı on dokuzdur. 
Bekirçavuşungavahlar ( $<$ Bekir Çavuş+un kavak+lar "Yukarıihsangazili köyünde bir koru adı.")

Dörtgavah (<dört kavak "Hatip köyünde bir koru adı.")

Garaavah (<kara kavak "Karlı köyünde bir mevki adı.”)

Garaavahçeşmesi (<kara kavak çeşmesi“ Karlı köyünde bir çeşme adı.”)

Gavaançeşme (<kavak+ı çeşme "Hacıçeşmesi köyünde bir çeşme adı.")

Gavaandepe ( $<$ kavak+1n tepe "Çakırlar köyünde bir tepe adı.")

Gavaandere (<kavak+1n dere "Kördeve köyünde bir dere adı.")

Gavaanpuñar (<kavak+1n pınar "Terzili köyünde bir çeşme adı.")+

Gavahderesi (<kavak deresi "Büyükçalıklı köyünde bir dere adı.")

Gavahderesi (<kavak deresi "Delice köyünde bir dere adı.")

Gavahlı (<kavak+lı "Aşağı ğerci köyünde bir mevki adı.")

Gavahlıh (<kavak+lık "Kayadibi köyünde bir koru adı.")

Gavahlıh (<kavak+lık "Susuz köyünde bir koru adı.")

Güccükgavahderesi (<küçük kavak deresi "Karacaahmetli köyünde bir derenin adi.")

Hacıgavaandepe ( $<$ hacı kavak+1n tepe "Hac1lı köyünde bir tepe adı.")

Haşimetingavahlar (<Haşmet'in kavak+lar "Küçükçalıklı köyünde bir koru adi.")

Köleninoğlunungavahlıh (<kölenin oğlunun kavak+lık “ Göçerli köyünde bir mevki adı.")

Teggavaandere (<tek kavak+1n dere "Çamdibi köyünde bir dere adı.")

Teggavah (<tek kavak "Çamdibi köyünde bir mevki adı.")

Kayısı (Armeniaca vulgaris Lam.) On beş metre kadar yükselebilen, beyaz veya pembe çiçekli, meyveli bir ağaçtır. (Baytop 2007: 291) Kayısı ile ilgili iki yer adı tespit edilmiştir.

Hayretgaysısı (<hayrat kayısı+sı "Hacıosmanlı köyünde bir bahçe adı.")

Kaysılık (<kayıs1+lık "Aydıngün köyünde bir bahçe adı.")

Keven (Astragalus sp. L.) Çok y1llık, dikenli ve yastık biçiminde dăg bitkileri. Dikenleri yakıldıktan sonra hayvan yemi olarak kullanılır. (Baytop 2007: 115) Keven ile ilgili bir yer adı tespit edilmiştir.

Kefencikeli $(<$ keven+cik eli "Belkavak köyünde bir mevki adı.")

Keme (Terfesia sp.) Asalak bir mantar olup bazı bitkilerin kökleri üzerinde yaşar. İç ve Güneydoğu Anadolu'da bulunmaktadır. Pişirilerek yenir. (Baytop 2007: 169) Keme bitkisi ile ilgili yedi yer ad1 tespit edilmiştir.

Kemedepesi $(<$ keme tepesi "Iğdecik köyünde bir tepe adı.")

Kemedepesi (<keme tepesi "Süleymanlı köyünde bir tepenin adı.")

Kemedepesi ( $<$ keme tepesi "Yakuplu köyünde bir tepe ad..")

Kemederesi (<keme teresi "Arifoğlu köyünde bir dere adı.")

Kemedüzlüğ ̈ü (<keme düzlüğü “Arifoğlu köyünde bir mevki adı.”) 
TÜBAR XLI / 2017-Bahar / Yerköy'de Bitki Adlarından Oluşan Yer Adları

Kemesekisi ( $<$ keme sekisi "Derebağ köyünde bir mevki adı.")

Kemesekisi (<keme sekisi "Küçüknefes köyünde bir mevki adı.")

Kırtıl (Genista carinalis GRIS.) Nehir, göl kenarlarında ya da seyrek ormanlık yerlerde yaşayan çok y1llı bitkilerdir. (http://www.bizimbitkiler.org.tr/v2/hiyerarsi.php?c=Genista) Kirt1l bitkisi ile ilgili iki yer adı tespit edilmiştir.

Kırtıllıtepe (<kırtıl+lı tepe "Topaç köyünde bir tepe adı.")

Girtıllınınbel $(<$ kırtıl $+11+$ nın bel "Susuz köyünde bir mevki adı.")

Lale (Tulipa sp. L.) Soğanlı, otsu, çok yıllık, kırmızı, sarı veya beyaz çiçekli bitkilerdir. Türkiye'de on sekiz kadar yabani lale türü yetişmektedir. Bazı türlerine özel adlar verilir. (Baytop 2007: 195) Lale ile ilgili üç yer adı tespit edilmiştir.

Lalelik (<lale+lik "Aşağıelmahacılı köyünde bir mevki adı.")

Lalelik (<lale+lik "Kahya köyünde bir mevki adı.")

Lalelik (<lale+lik "Terzili köyünde bir mevki ad..")

Mamık (Prunus spinosa L.) Çakal eriği, deli erik. Meyveleri siyahımsı mavi renklidir. (Baytop 2007: 101) Yöredeki adı "mamıh”tır. Ekşileri ile arabaşı çorbası yapılır. Bu bitki adı ile bir yer adı tespit edilmiştir.

Mamıhözü (<mamık özü "Köycü köyünde bir dere adı.")

Menekşe (Viola sp. L.) Bir veya çok yıllık otsu bitkilerdir. Çiçekler beyaz, sar1 ve mor renklidir. (Baytop 2007: 204) Bu bitki adı ile ilgili bir yer adı tespit edilmiştir.

Menekşederesi (<menekşe deresi "Karacaağaç köyünde bir derenin ad1.")

Mercimek (Lens culinaris Medik) Alçak boylu bir yıllık otsulardır. Çiçekleri küçük, mavimsi beyaz veya eflatun rengindedir. Altı türü vardır, ülkemizde beş türü yayılış gösterir. (Seçmen-vd.1998: 239) $\mathrm{Bu}$ tahılla ilgili iki yer adı tespit edilmiştir.

Mercimekdepe (<mercimek tepe "Hacıçeşmesi köyünde bir tepe adı.")

Mercimekdepe ( $<$ mercimek tepe "Yukarıeğerci köyünde bir tepenin ad1.")

Meşe (Quercus sp. L.) Genellikle kıı̧ın yapraklarını döken bazı türlerine özel adlar verilen ağaç türüdür. (Baytop 2007: 207) Meşe ile ilgili bir yer adı tespit edilmiştir.

Meşelik (<meşe+lik "Kördeve köyünde bir koru ad..")

Pamuk (Gossypium L.) Bir yıllık otsular veya yarıçalımsılardır. Tohumların üzerindeki beyaz tüyler pamuk olarak kullanılır. (Seçmenvd.1998: 205) Pamuk ile ilgili üç yer adı tespit edilmiştir. Burada dikkat edilecek husus yer adına mecazi anlamda pamuk isminin ve- 
rilmemiş olmasıdır. Tespit edilen bu yer isimlerinin kendisinde veya çevresinde pamuk üretiminin bizâtihi kendisi yapılmıştır.

Pamuhlu (<pamuk+lu "Eskiyerköy köyünde bir mevki adıdır.")

Pamuhluaya (<pamuk+lu kaya "Çayköy köyünde bir tarla adı.")

Pamuhluderesi (<pamuk+lu deresi "Kocaoğlu köyünde bir dere adı")

Pancar (Beta vulgaris L.) Şeker pancarı. Büyük ve etli bir yumru olan köklerinden şeker elde edilir. (Seçmen-vd.1998: 192) Pancar ile ilgili bir yer adı tespit edilmiştir.

Pancarlıh (<pancar+lık "Poyraz köyünde bir tarla adı.")

Pitrak (Xanthium spinosum L.) Bir yıllık, otsu, meyvesi üzerinde kuvvetli dikenleri bulunan küçük bitkidir. (Baytop 2007: 226) Bu bitki adı ile ilgili bir yer adı tespit edilmiştir.

Pıtırahlıseki (<pıtrak+1ı seki "Çayköy köyünde bir mevki adı.")

Söğüt (Salix sp. L.) Kışın yapraklarını döken, özellikle dere kenarlarında yetişen bir ağaç türüdür. Bazı türlerine özel adlar da verilir. (Baytop 2007: 248) Yörede kavaktan sonra yer adlarında en çok ismi geçen ağaç türüdür. On beş yer adında tespit edilmiştir.

Söğutlü (<söğüt+lü "Terzili köyünde bir mevki adı.")

Söğütlü (<söğüt+lü "Aşağıelmahacılı köyünde bir koru adı.")

Söğütcük (<sögüt+cük "Çakırhacılı köyünde bir çeşme adı.")

Söğütlü (<söğüt+lü "Kahya köyünde bir mevki adı.")

Söğütlüdepesi (<söğüt+lü tepesi "Kahya köyündeki bir tepe adı.")

Söğütlüpuñar (<söğüt+lü pınar "Büyükçalıklı köyünde bir çeşme adı.")

Söğütlüpuñar (<söğüt+lü pınar "Terzili köyünde bir çeşme adı.")

Söötcük (<söğ̈̈t+cük "Zencir köyünde bir çeşme adı.")

Söötcükyolu (<sögüt+cük yolu "Zencir köyünde bir yol adı.")

Söötlööz (<söğüt+lü öz "Cakcak köyünde bir tarla adı.")

Söötlöözü (<söğüt+lü özü "Kördeve köyünde bir dere adı.")

Söötlüçeşme (<söğüt+lü çeşme "Eskiyerköy köyünde bir mevki adı.")

Söütlüpuñar (<söğüt+lü pınar "Derecik köyünde bir çeşme adı.")

Söütpuñarı (<söğüt pınarı "Hacıuşağı köyünde bir çeşme adı.")

Teksööt (<tek söğüt "Harkaşan köyünde bir mevki adı.)

Tere (Lepidium sativum L.) Ülkemizde kültürü yapılan ve yaprakları salata olarak kullanılan bir yıllık bitki. (Seçmen-vd.1998: 218) Tere ile ilgili bir yer adı tespit edilmiştir.

Tereli (tere+li "Harkaşan köyünde bir mevki adı.")

Tülü (Crocus sp.L. ) Bir çeşit çiğdem türü. (Baytop 2007: 72) Toprak altında yetişen ak, yumru gövdesi yenilen, ince yeşil yapraklı bir çeşit bitkidir. Tülü ile ilgili dört yer adı tespit edilmiştir.

Güccüktülüçe (<küçük tülü+çe "Hac1osmanlı köyünde bir tepe adı.")

Tülüçe (<tülü+çe "Hacıosmanlı köyünde bir tepe adı.") 
TÜBAR XLI / 2017-Bahar / Yerköy'de Bitki Adlarından Oluşan Yer Adları

Tülüçenintürbe $(<$ tülü+çe+nin türbe "Hacıosmalı köyünde bir türbe ad1.")

Tülüdepesi (<tülü tepesi "Terzili köyünde bir tepe adı."

Üzerlik (Peganum harmala L.) Otuz yetmiş santimetre yükseklikte, çok yıllık, otsu ve beyaz çiçekli bir bitki. Tohumları tütsü olarak kullanılır. (Baytop 2007: 273) Üzerlik ile ilgili bir yer adı tespit edilmiştir.

Üzerlikdepesi (<üzerlik tepesi "Harkaşan köyünde bir tepe adı.")

Üzüm (Vitis vinifera L.) Ülkemizde genellikle Trakya, Batı ve Güney Anadolu'da kültürü yapılır. Glikoz bakımından zengin olan meyveleri iyi bir besin kaynağıdır. (Seçmen vd. 1998: 252) Bu meyve ile ilgili bir yer adı tespit edilmiştir.

Üzümbağları (<üzüm bağları "Topaç köyünde bir bağ adıdır.")

Yandak (Ononis spinosa L.) Kayışkıran. Çok yıllık, dikenli ve pembe çiçekli bir bitkidir. Kökleri idrar artırıcı ve taş düşürücü olarak tanınmıştır. (Baytop 2007: 164) Yandak ile ilgili bir yer adı tespit edilmiştir.

Yandaklı (<yandak +1 " "Salihli köyünde bir mevki adı.")

Yonca (Trifolium sp. L.) Bir veya çok yıllık, otsu ve yaprakları genellikle üç yapraklı bitkilerdir. Bu bitki adı ile ilgili iki yer adı tespit edilmiştir.

Yoncalıh (<yonca+lık "Yukarıelmahacılı köyünde bir tarla adı.")

Yoncalık (<yonca+lık "Aydıngün köyünde bir tarla adı."

\section{Sonuç}

Türkçede yer adı verme geleneklerinden biri de o yörenin bitki örtüsüdür. Yerköy mikrotoponimlerinin incelendiği bu makalede Yerköy halkının bir yere isim vermede kullandığı araçlardan biri de yaşadığı bölgenin bitki örtüsü olmuştur. Derlenen bu fitotoponimlerin bir kısmının ağızlarda, bir kısmının standart dilde, bir kısmının da hem ağızda hem standart dilde yaşadığı görülmektedir. Ağızlarda yaşayan bu bitki adlarına Derleme Sözlüğü'nde rastlanılmış; fakat bu bitki adları Yerköy'den tespit edilmemiştir. Tespit ettiğimiz bu bitki adlarından en yaygın olanı "kavak" tır. Kavak, on dokuz yer adında tespit edilmiştir. Kavağı on beş yer adıyla söğüt ve on iki yer adıyla iğde takip etmektedir. Yer adlarında geçen bitkilerden pamuk dışındaki tüm bitkiler bölgede varlığını sürdürmektedir.

Bu konuda önemli bir diğer husus da yer adları ile birlikte yöresel bitki adlarının da unutuluyor olmasıdır. Canlı bir vesika olan yer adlarının 
tespiti ile bu bitki adlarının gelecek kuşaklara unutulmadan aktarılması sağlanmıştır.

\section{KAYNAKÇA}

AKSOY, A., BUDAK, Ü. (2004), "Yerköy (Yozgat) ve Civarındaki Bazı Bitkilerin Yöresel Adları ve Kullanımları", Her Yönüyle Yerköy Sempozyumu Kitabl, Yerköy Kaymakamlığı.

BAYTOP, Turhan (2007), Türkçe Bitki Adları Sözlügü, TDK Yay., Ankara , s.29.

DELİGÖZ A., GÜLTEKIN H.C., YILDIZ D., GÜLTEKIN Ü.G., GENÇ M. (2007), "Karaçalı ve Hünnap Tohumlarının Çimlendirilmesi Üzerine $\mathrm{GA}_{3}$, Çıtlatma ve Ekim Zamanının Etkileri, SDÜ Orman Fakültesi Dergisi, Seri:A, Sayı:2, s.51-60.

Derleme Sözlüğü (1993), C. 1-12, TDK Yay., Ankara.

SEÇMEN, Ö., DEMIRCI Y.,TÜRK G.,LEBLEBICİ E. (1998), Tohumlu Bitkiler Sistematiği, Ege Ünv. Basımevi, İzmir.

ŞAHIN, İbrahim (2011), Yeradıbilimi "Araştırmalarında Mikrotoponiminin Yeri, Önemi ve Araştırma Yöntemi: Tırnak Köyü (İçel/Gülnar) Örneği”, Turkish Studies, Volume 6/1, s.1808.

http://www.bizimbitkiler.org.tr/v2/hiyerarsi.php?c=Genista

Vikipedi, https://tr.wikipedia.org/wiki/Asma. 